\title{
La historia de la educación preescolar desde la perspectiva de la larga duración
}

The History of Pre-school Education from a Long-term Perspective

A história da educação pré-escolar em uma perspectiva de longa duração

\section{Carmen Sanchidrián-Blanco* iD orcid.org/0000-0003-4208-2182}

Para citar este artículo: Sanchidrián-Blanco, C. (2021). La historia de la educación preescolar desde la perspectiva de la larga duración. Revista Colombiana de Educación, l(82), 301-322. https://doi.org/ 10.17227/rce.num82-10750

\begin{tabular}{rr}
\hline (c) $\left(\begin{array}{l}\text { RY } \\
\text { NG }\end{array}\right.$ & Recibido: $22 / 11 / 2019$ \\
Evaluado: $01 / 09 / 2020$ \\
$19 / 07 / 2020$ \\
$01 / 09 / 2020$
\end{tabular}

* Doctora en Filosofía y Ciencias de la Educación. Profesora catedrática de la Universidad de Málaga, España. 


\begin{abstract}
Resumen
Este artículo de reflexión presenta un marco para facilitar los estudios de historia comparada de educación preescolar y de larga duración, centrados en un país o región a partir de la revisión sistemática de investigaciones sobre la historia de la educación infantil. Este proceso de revisión se desarrolló teniendo en cuenta las etapas de los diferentes modelos de educación preescolar que pueden ser comunes entre países con duraciones diferentes, señalando tres etapas que abarcan desde la creación de las primeras instituciones hasta su generalización. Se revisan esas tres etapas en el caso español, sin intentar presentar la historia de la educación preescolar en España durante casi doscientos años, sino indicando algunos hitos, debates, contribuciones o normas legales significativas que permitan entender mejor esa historia y establecer puentes para una historia comparada. Tanto la teoría de dependencia de paso como la utilización de modelos permiten obtener una visión global de los procesos estudiados y percibir las decisiones que, tomadas en un momento dado, condicionan gran parte de esa historia. La utilización de este marco en estudios de larga duración en otros países permitirá ajustar las fases descritas y demostrar su eficacia.
\end{abstract}

\section{Palabras clave}

Historia de la educación; educación preescolar; política educativa; educación comparada; otros países

\section{Keywords}

Educational history; early

childhood education; educational policy; comparative education; foreign countries

\begin{abstract}
This article presents a framework to facilitate, on one hand, comparative history studies of pre-school education, and, on the other hand, long-term studies focused on a country or region. Based on the systematic review of the history of early childhood education and taking into account stages that may be common across countries depending on different models of preschool education with different durations, three stages are identified, ranging from the creation of the first institutions to their universalisation. We review these three stages in the Spanish case. We do not pretend to offer a two-hundred-year Spanish preschool education history, but to indicate some significant milestones, debates, contributions or legal norms that allow a better understanding of that history to establish bridges for a comparative history. Both the path dependency theory and the use of models will allow one to obtain a global perspective of the process studied and to perceive the decisions that, taken at a given time, affects much of their future history. The use of this framework in long-term studies in other countries will make it possible to adjust the steps described and to demonstrate its effectiveness.
\end{abstract}

\section{Resumo}

Este artigo apresenta um quadro que pode facilitar, por um lado, os estudos de história comparada da educação pré-escolar e, por outro, estudos de longa duração centrados em um país ou região. Valendo-se de uma análise sistemática da história da educação infantil e, tendo em conta as etapas que podem ser comuns entre os diferentes países em função dos distintos modelos de educação pré-escolar, mas com uma duração diferente, foram identificadas três etapas que vão desde a criação das primeiras instituições até à sua generalização. Essas três etapas são revistas no caso espanhol. Não se tenta apresentar a história da educação pré-escolar em Espanha durante quase duzentos anos, mas indicar alguns marcos, debates, contribuições ou normas legais significativas que permitam entender melhor essa história e estabelecer pontes para uma história comparada. Tanto a teoria de dependência de passo como a utilização de modelos permitem obter uma visão global dos processos estudados e perceber as decisões que, tomadas em um dado momento, condicionam então grande parte dessa história. A utilização deste quadro em estudos de longa duração em outros países permitirá ajustar as fases descritas e demonstrar a sua eficácia.

\section{Palavras-chave}

história da educação; educação pré-escolar; política educacional; educação comparada; outros países 


\section{Introducción}

Desde la perspectiva histórica y pedagógica sería útil contar con un marco general que facilitase el estudio comparado de la historia de la educación preescolar, para ello, la teoría de la dependencia de paso (path dependency) (David, 2007; Pierson, 2000) puede servirnos para entender mejor el desarrollo de la educación preescolar en cualquier contexto. De acuerdo con ella, Valiente, por ejemplo, planteaba que, en España en 1975 los gobiernos democráticos encontraron que la educación preescolar contaba ya con una estructura (centros, docentes), conceptos y organización (2009) y que era más fácil ampliar la estructura existente dentro del sistema educativo que crear una nueva (Mahoney, 2000). Esta teoría permite explicar por qué en determinados países la educación preescolar está o no dentro del sistema educativo o las instituciones que se proponen en cada caso. Por otra parte, Scheiwe y Willekens (2009) se refieren a dos modelos de institucionalización de la educación preescolar: el modelo educativo, basado en la idea de que los niños necesitan educación pública antes de los seis años y, por tanto, no se orienta a una clase social concreta, y el modelo de conciliación familiar que busca promover la conciliación del cuidado de los niños con el trabajo remunerado de los padres y que se centra en los niños cuyos padres no pueden atenderlos, casi siempre por estar ambos trabajando.

A partir de aquí, en síntesis, revisadas investigaciones ya realizadas sobre historia de la educación preescolar relativas en su mayoría a un país o período determinados, plantearemos tres etapas que se pueden establecer en esa historia cuya duración variará de un país a otro: la primera es el periodo de creación de las primeras instituciones con una acentuada misión asistencial; la segunda se caracteriza por ser cuando la educación preescolar deja de ser solo para los niños pobres cuyas madres no pueden atenderlos y pasa a ser vista como "conveniente", positiva para todos los niños antes de la escuela primaria, pero la mayoría de los niños que acceden a ella lo hacen por razones extra educativas; y la tercera es el periodo de generalización, de extensión de la educación preescolar. El foco de este estudio es la educación institucional de los niños en los años previos al comienzo de la escuela primaria ya que tanto el estudio de las políticas educativas para niños de cero a dos años como las iniciativas cuyo principal fin no es la educación (Valiente, 2011) merecen un estudio aparte.

No puede hacerse historia de la educación, en general, sin considerar factores económicos, sociológicos, religiosos, políticos, etc., y en la historia de la educación preescolar es necesario tener en cuenta, además, la historia de la infancia (más amplia que la historia de la educación preescolar), la historia de las mujeres, la historia de la urbanización, la historia de la educación, etc. Generalizando, como punto de partida para establecer 
posibles comparaciones en las que se aprecien tanto las diferencias como las similitudes en el ritmo de los procesos y en los caminos tomados, partimos de que los sistemas educativos de Europa occidental, que comparten muchas características con los sistemas educativos iberoamericanos, nacen bajo los principios de secularización, uniformidad y centralización en la primera mitad del siglo xix. Sin embargo, cada uno de los nacientes sistemas educativos, de los que forma parte la educación preescolar, tiene desde el principio caracteres diferenciales. El sistema educativo español apareció a la vez que en países de su entorno; la declaración de la escuela primaria como obligatoria en 1838 fue relativamente temprana (Viñao, 2002), pero era débil, del mismo modo que lo era el Estado frente a la Iglesia (la católica en este caso), y su desarrollo fue tardío con relación a países como Francia, Gran Bretaña, Alemania o Estados Unidos, aunque tuvo una posición ligeramente adelantada con relación a los países iberoamericanos (Ossenbach, 2001) lo que habrá que tener en cuenta en los estudios comparados.

La hipótesis de partida es que pueden distinguirse las tres fases, aunque con diferencias cronológicas no solo entre los distintos países sino dentro de zonas de cada país en función de los niveles de industrialización y de desarrollo de la educación formal. La segunda hipótesis es que el papel jugado por la Iglesia y el Estado es decisivo para explicar el desarrollo de la educación preescolar. Ese papel es determinante siempre y las tensiones entre ambos, la ideología dominante en cada momento y factores de diversa índole son los que explican la particular historia de la educación por lo que ofrecemos algunas pinceladas sobre este tema a lo largo del período estudiado.

En este artículo se describen y explican las tres etapas citadas en el caso español, pero sería una interesante línea de investigación probar cómo funcionan en Iberoamérica además de seguir trabajando sobre esto en Europa y Norteamérica (Willekens et ál., 2015).

En España abarcarían, aproximadamente, desde 1838 hasta 1874, desde ahí hasta 1975 y desde esa fecha hasta hoy. En este artículo se intenta proporcionar un marco que facilite estudios de larga duración que son los que permiten obtener una visión más global de los procesos estudiados y percibir las decisiones que, tomadas en un momento dado, condicionan luego en gran medida esa historia. Dada la extensión del período estudiado, el objetivo no es presentar la historia de la educación preescolar en España durante casi doscientos años, tema sobre el que hay numerosas publicaciones ya recogidas en una revisión historiográfica del tema (Sanchidrián, 2010), sino indicar algunos hitos, debates, contribuciones o normas legales significativos que permitan entender mejor esa historia y establecer puentes para una historia comparada a partir de la revisión de publicaciones anteriores (Sanchidrián, 1991; 2009; 2015). 


\section{Primera etapa (1838-1874): Recoger y educar}

La primera etapa comprende desde que se inaugura la primera escuela pública de párvulos hasta que se hacen patentes los intentos por introducir la metodología froebeliana. Está vinculada a la incipiente industrialización y al nacimiento del sistema educativo estatal, y se orienta a los niños pobres cuyas madres no pueden atenderlos porque están trabajando.

En 1838 se fundó la "Asociación para propagar y mejorar la educación del pueblo", presidida por Pablo Montesino, en la que una sección se dedicó a promover la creación de escuelas de párvulos y a supervisarlas. La primera, la denominada escuela de Virio, se inauguró en Madrid en 1838. Montesino, médico liberal exiliado durante la década ominosa (18231833), a su vuelta, trató de divulgar las ideas que acerca de la educación preescolar (también primaria y secundaria) había conocido sobre todo en Inglaterra. Él fue el inspirador de la Ley de 21 de julio de 1838 de enseñanza primaria que declaraba obligatoria la primera enseñanza para niños y niñas desde los 6 hasta los 9 años, establecía que para ser maestro era preciso obtener el título correspondiente en las escuelas normales y se refería a las escuelas de párvulos por primera vez en un texto legal, aunque sin darles ninguna financiación pública. También fue el autor, en 1840, del Manual para maestros de escuelas de párvulos, primer libro de este tipo, que serviría de guía a los maestros de estas escuelas y de las primarias durante las primeras décadas del sistema educativo (Sanchidrián, 1985).

Cuando aparecieron las primeras escuelas de párvulos, tanto en España como en otros países de nuestro contexto (Burger, 2014; Luc, 1982; Whitbread, 1972), lo hicieron con una doble finalidad claramente explicitada, la asistencial y la educativa, hecho que ha condicionado fuertemente todo su desarrollo posterior en lo relativo a sus destinatarios, contenidos y docentes (formación, funciones e imagen del maestro y la maestra de párvulos).

La definición de "escuela de párvulos" hecha por el propio Montesino quizá sea la que mejor recoja las características de esta naciente institución. Indica su doble finalidad, recoger y educar, la edad de los niños a que se destina, dos a seis años, y su clase social, pobres:

Las escuelas de párvulos son unos establecimientos destinados a recoger y dar educación a los niños pobres de ambos sexos de dos a seis años de edad; es decir, durante aquella época de la vida en que pueden pasar todo el día o la mayor parte de él sin la madre o la nodriza y al cuidado de una persona que haga las veces de madre común. (1840, p. 67)

Este enfoque era el predominante en estos momentos iniciales, tanto en España como en países como Gran Bretaña o Francia (Sanchidrián y Ruiz Berrio, 2011). Se intentaba usar la educación como medio de reforma y mejora social, idea típica del período liberal. Se plantea la creación de 
escuelas de párvulos para los hijos de las familias más humildes que son los que necesitan de ellas, aunque se dice que en "el interés común de las familias [acomodadas] creará luego escuelas de párvulos destinadas especialmente para estas clases" (Montesino, 1840, pp. 13-14); serían, pues, otras escuelas, no las mismas, y el establecimiento de las primeras ya iba a resultar ventajoso para las familias pudientes puesto que de ellas saldrían los que luego serían "buenos criados", "buenas nodrizas", "amas de gobierno", etc. (Montesino, 1840, p. 15). Es obvio que, en esos momentos, la escuela no era ni un lugar de integración entre clases sociales ni una vía de ascensión social.

En realidad, la mayoría de las escuelas de párvulos españolas del $x I x$, estuvieron alejadas de los nuevos modelos que iban llegando y tampoco seguían realmente el modelo propuesto por Montesino dado que los maestros o maestras a menudo solo eran capaces de repetir mecánicamente rutinas observadas en otras clases. Dadas las condiciones materiales y personales con que contaban, clases con 100 o 150 niños en espacios reducidos a cargo de un maestro y una maestra que le "ayudaba" (Sanchidrián, 2017, p. 19), casi lo único que los maestros podían proponerse era impedir que los niños se ensuciaran, hablaran o hicieran ruido. Los métodos empleados tanto en las primeras escuelas de párvulos, en las salles d'asile francesas y en las infant schools británicas, tomaban muchos elementos de la enseñanza mutua, especialmente los toques de silbato, las palmadas, los movimientos conjuntos, la utilización de los mayores como monitores, etc., y es dudoso que se cumplieran las funciones que tenían asignadas.

En España, las relaciones entre el Estado y la Iglesia habían sido siempre estrechas como lo prueban las constituciones aprobadas en 1812, 1837 y 1876 donde se declaraba el catolicismo como la religión del Estado y en la de 1869, donde el catolicismo no tenía ese carácter, pero sí se obligaba al Estado a mantenerlo (Martínez-Torrón, 2005). La creación del sistema educativo se planteó en las primeras décadas del siglo xIx, justo después de que la Iglesia sufriera importantes pérdidas como la abolición de la Inquisición, la expulsión de los jesuitas (1767-1814), y las desamortizaciones liberales de Mendizábal y Madoz, por las que tierras y bienes inmuebles de la Iglesia pasaron a manos del Estado y de particulares. Muchos de esos edificios se destinaron a centros docentes (Institutos, Escuelas de Bellas Artes, Escuelas Normales, escuelas...), pero tras la llegada al poder de los moderados en 1844, los conflictos empezaron a disminuir al obtener determinados privilegios también en el ámbito educativo. El Concordato de 1851 concedía a la Iglesia exenciones de impuestos, subvenciones anuales, el derecho de que todas las enseñanzas estuvieran de acuerdo con la doctrina de la Iglesia y fuertes privilegios en enseñanza secundaria, la que más le interesaba a la Iglesia ya que era un nivel profundamente elitista 
y orientado a la enseñanza universitaria. Con la Ley Moyano, 1857, que Boyd cita como una secuela del Concordato de 1851 y como el resultado de élites conservadoras alarmadas por las revoluciones democráticas que estaban produciéndose en Europa (1997), la Iglesia mantuvo el derecho a controlar tanto la enseñanza como los libros de texto y la enseñanza de la religión siguió siendo obligatoria (Viñao, 2014); asimismo, se les garantizó el derecho a crear centros privados de educación preescolar, primaria y secundaria y se mantuvo a la educación en España alejada de los procesos secularizadores defendidos por los progresistas. Esta ley situaba la educación preescolar como el primer nivel de la educación primaria de forma que la educación preescolar forma parte del sistema educativo desde sus orígenes. Su artículo 105, recomendaba que los ayuntamientos con más de 10000 habitantes establecieran al menos una escuela de párvulos, pero los ayuntamientos mostraron escaso interés por la educación preescolar de forma que la mayoría de niños menores de seis años escolarizados lo estaban en escuelas primarias, no en escuelas de párvulos.

\section{Segunda etapa (1874-1975): Institucionalización}

Esta etapa se divide en tres: la primera abarca las últimas décadas del siglo xIX y ahí se evidencia la estéril lucha ideológica entre la Iglesia y el Estado; la segunda, hasta el estallido de la Guerra Civil en 1936 y la tercera, hasta 1975. Es quizá la menos espectacular, a pesar de ser la más larga; fue cuando la educación preescolar dejó de ser considerada solo para los niños pobres cuyas madres no pueden atenderlos y pasó a ser vista como "conveniente" para todos los niños antes de la escuela primaria. La elección de la primera fecha viene motivada por los comienzos de difusión del modelo froebeliano en el que lo educativo prima sobre lo asistencial y la de 1975 por ser el final del franquismo, poco después de la publicación de la Ley General de Educación (LGE) de 1970 que cambió sustancialmente la estructura del sistema educativo. El camino recorrido en esta "segunda etapa" es el más específico de cada país y tiene características propias, solo explicables si situamos la educación preescolar en su particular contexto. En este periodo el Estado y la Iglesia lucharon por el control de la educación, pero ninguno de ellos tuvo un interés especial por la educación preescolar, mientras que la enseñanza secundaria y universitaria focalizaron la mayor parte de sus esfuerzos.

En estos 100 años se asiste a un desarrollo cuantitativo lento de la educación preescolar en la que la iniciativa privada fue fundamental, ya que solo a partir del curso 1977-1978 el número de niños de 2 a 5 años que asisten a centros públicos es mayor que el de los que lo hacen a centros privados (Sanchidrián, 1985). Los porcentajes de escolarización de los niños de esas edades se mantuvieron en torno al $25 \%$ desde finales 
del xIx y hasta bien entrados los años sesenta (Willekens y Scheiwe, 2020). Los 40 años del franquismo (1936-1975) supusieron en este campo, como en todo, un freno e incluso una involución debido, especialmente, al papel que se le adjudicaba a la mujer en la sociedad; la escolarización en educación preescolar no llegó a generalizarse en gran parte por los planteamientos ideológicos acerca de la participación de las mujeres en el mundo laboral: el trabajo de las mujeres se aceptaba si la mujer no tenía cargas familiares (solteras o sin hijos) o si era estrictamente necesario. Esto hacía que la mayoría de las mujeres trabajadoras lo hicieran en el sector primario o secundario.

\section{Conservadores y liberales frente a la educación preescolar (1874-1901)}

En estos años, España era uno de los países más pobres de Europa occidental y podía invertir en educación menos que la mayoría de los países de nuestro entorno, como Francia o Gran Bretaña. Sin embargo, esto no explica por sí solo el escaso desarrollo de la educación pública puesto que dentro del propio país las diferencias eran muy grandes en aspectos fundamentales como alfabetización y escolarización no correlacionando estas variables con niveles de riqueza. En el siglo xIx, el Estado regulaba la educación, pero el cumplimiento de las normas dependía de los ayuntamientos y estos no tenían, en general, ni interés ni medios reales (Fernández Soria, 2013). El sistema educativo español siguió el modelo centralista napoleónico: "el Estado se reservaba el poder de dirigir, planificar, controlar y ejecutar, aunque a la hora de aplicar la norma convoque al municipio obligándole a crear y mantener las escuelas que le corresponden por ley" (Fernández Soria, 2013, p. 179).

A lo largo de estos años, la Iglesia y el Estado estuvieron más preocupados por afirmar su soberanía en la educación que por mejorarla efectivamente. El Estado mantuvo a la educación primaria en una situación de abandono y la Iglesia se hizo fuerte especialmente en el campo de la secundaria (Castells, 1973). En realidad, ambas instituciones discreparon en la teoría, pero en la práctica estuvieron de acuerdo en mantener abandonada la educación pública y demostraron no ser capaces de afrontar la resolución del problema educativo (Puelles, 1980). Solo así se puede explicar que, siendo la educación primaria obligatoria en España desde 1838, en 1900 no supiera leer y escribir el 56,07\% de los mayores de diez años y no asistiera a la escuela la mitad de los niños en edad escolar.

Uno de los hechos que caracteriza este periodo es el intento de impulsar la educación preescolar mediante la aplicación de las teorías de Froebel que habían sido divulgadas por Carderera (1859), Badouin (1866) y López Catalán (1864-1867), aunque fue García Navarro quien más contribuyó a 
su difusión (1874 y 1879); esta estuvo vinculada a la del krausismo y a la Institución Libre de Enseñanza, lo que explica la buena acogida que tuvo ente los intelectuales liberales del momento (Ruiz Berrio, 1982).

En 1874 se promulgó la Orden de 31 de octubre que disponía que "en la escuela Normal Central de Párvulos se proceda a practicar un ensayo de la institución debida a Federico Froebel". Por tanto, en 1874 coincidieron la obra de García Navarro y la intervención del gobierno dando carácter "oficial" al ensayo que se estaba haciendo en la escuela de Virio, en muy malas condiciones ya que se hizo en una escuela de párvulos creada según el modelo de Montesino y ni el espacio, ni los materiales ni el número de alumnos permitían pensar en algo similar a un jardín de infancia.

En Barcelona, Julián López Catalán, director de la escuela Modelo de Párvulos y uno de los mayores defensores de la educación de los párvulos en los años sesenta, había incorporado la educación higiénica, los juegos, la gimnasia, la educación sensorial y la utilización del material educativo de Froebel tratando de modificar la idea que existía de que la educación de párvulos no era importante desde el punto de vista escolar ni desde el punto de vista educativo. En 1864 publicó El arte de educar donde dedicaba parte del tercer tomo a los métodos y dones de Froebel, pero en 1887, en El froebelianismo puro y neto, se manifestó en contra de este (Martínez Ruiz Funes, 2013).

La legislación en estos años, caracterizados por el turno en el gobierno de conservadores y liberales, fue un constante hacer y deshacer con relación a este tema. Podemos hablar de reforma y contrarreforma: en el bloque de la legislación reformista tenemos, además de la Orden citada, los Reales Decretos de 31 de marzo de 1876 y 17 de marzo y 13 de agosto de 1882 y 11 de agosto de 1887 y en la contrarreforma tenemos los Reales Decretos de 4 de agosto de 1884 y 16 de septiembre de 1889 (Dorado Soto, 1984). Los primeros, básicamente, intentaban introducir la metodología froebeliana, mientras que los otros querían mantener el estado de cosas establecido en la ley Moyano que daba a la educación preescolar un estatus inferior a la primaria.

Ahora bien, no se puede simplificar y equiparar partido conservador con legislación conservadora y partido liberal con legislación reformista, lo que evidencia, más aún, "la falta de programa, de criterio, de miras, de ideas de nuestros políticos en materia de enseñanza" que resumía así las incoherencias de los legisladores:

dos ministros conservadores [...] preparan y realizan el establecimiento de la enseñanza froebeliana y de los Jardines de la Infancia, y otro ministro del mismo partido echa por tierra todo lo edificado sobre esas bases; dos ministros liberales [...] afirman lo hecho por aquellos 
ministros conservadores, Ilevándolo a sus naturales consecuencias, y otro ministro, también el partido liberal [...] acaba con lo hecho por sus correligionarios. (García Navarro, 1913, p. 347)

En paralelo con ese tejer y destejer legislativo, tuvo lugar un interesante debate teórico entre los defensores de las escuelas de párvulos (según el modelo de las infant schools británicas adaptadas a España por Montesino) y los de los Jardines de Infancia, Kindergarten. Aparentemente se discutía qué modelo era "mejor", con cuál se aprendía más. Los defensores del modelo de las escuelas de párvulos, López Catalán al frente (1887), afirmaban que ese modelo era mejor porque era más parecido al de las escuelas primarias y se burlaban de los que pensaban que los niños aprendían plegando, recortando y jugando. Los defensores de Froebel afirmaban que los niños aprendían incluso más con su método, revelando que ambos grupos tenían una visión academicista de la educación preescolar. En el fondo de las críticas a Froebel estaba presente la cuestión religiosa (Sanchidrián, 2015), pero no era una mera cuestión de protestantes frente a católicos, ya que lo que no se aceptaba era unir trabajo y juego y que eso fuera el primer paso hacia la escuela obligatoria (Sommer et ál., 2010).

En ocasiones, más que una descalificación global de la metodología froebeliana, se pedía que adaptaran a "nuestra forma de ser" los "métodos y procedimientos" de Froebel del mismo modo que Montesino había acomodado los de Wilderspin transformando escuelas protestantes en escuelas católicas de párvulos. Estos debates fueron distanciando las escuelas de párvulos del modelo asistencial de la primera oleada para convertirse en escuelas primarias "reducidas" en contenidos, poco adaptadas a las necesidades específicas de los niños de cuatro a seis años y ajustadas a un patrón academicista, similar al utilizado en la enseñanza elemental o primaria (Martínez Ruiz Funes, 2013; Viñao, 1983).

\section{El Regeneracionismo y la Escuela Nueva frente a la educación preescolar}

Los enfrentamientos entre la Iglesia y el Estado se mantuvieron en el primer tercio del siglo $x x$, en unos años de fuerte inestabilidad política como atestiguan los 26 ministros de Instrucción Pública que hubo entre 1900 y 1915 y los 27 que hubo entre 1915 y 1931. Los regeneracionistas (Joaquín Costa, Lucas Mallada y Ricardo Macías Picavea, entre otros) hicieron una profunda crítica del sistema e instituciones del país y vieron en la educación una herramienta clave para la regeneración nacional. La Iglesia siguió contando con una implantación sólida en la enseñanza española, pero tuvo que hacer frente a un fuerte movimiento secularizador. La situación de la educación pública primaria era tan deplorable que fue necesario concentrar ahí los esfuerzos por lo que los avances en la educa- 
ción preescolar no fueron grandes. Los defectos de base de la educación española se mantuvieran a pesar de existir un clima general favorable a las reformas educativas.

El siglo xx comenzó con importantes medidas como fueron los primeros ensayos de graduación de la enseñanza, la creación del Ministerio de Instrucción Pública y Bellas Artes y la asunción, por parte del Estado, del pago de los sueldos de los maestros. El Real Decreto de 26 de octubre de 1901 consideró a la educación preescolar legalmente como el primer grado de la escuela primaria que quedaba dividida en párvulos, elemental y superior (art. 2); también establecía que cada uno de estos tres grados abrazaría todas las materias indicadas en el artículo 3, "distinguiéndose únicamente por la amplitud del programa y por el carácter pedagógico y duración de los ejercicios" (artículo 4). A partir de aquí el modelo predominante será una escuela primaria "reducida" que ha provocado durante décadas una doble y tensa relación con la enseñanza primaria de diferenciación y supeditación (Viñao, 2004).

La asistencia de niños menores de 6 años a la escuela primaria se produjo desde que se estableció la escuela primaria obligatoria (en 1850, asistían a las escuelas primarias 778477 alumnos de los que 174379 tenían menos de 6 años); en 1908 estaban matriculados 317658 niños de 3 a 6 años (el $24 \%$ de los niños esas edades) que asistían mayoritariamente a escuelas primarias públicas dado que solo figuraban 1024 escuelas de párvulos (Martínez Ruiz Funes, 2013). El Real Decreto de 17 de julio de 1913 fijaba la edad para la asistencia a escuelas primarias y escuelas de párvulos intentando poner fin a la mezcla existente de edades en unas y otras:

Diferentes disposiciones han fijado la edad para la asistencia a las escuelas primarias y de párvulos, pero es público y notorio que los límites marcados en esas disposiciones no son por lo general respetados en la práctica [...] Tal ocurre principalmente con la admisión en las escuelas de párvulos de niños y niñas mayores, no solo de seis y siete años sino aun de nueve, diez y más.

Tras esta norma, las escuelas de párvulos admitirían niños de tres a seis años salvo en casos de retraso mental y la enseñanza en estas escuelas sería la que correspondía a la edad y desarrollo mental de los alumnos. (Martínez Ruiz Funes, 2013, pp. 102-103)

Lentamente se iban dando pasos hacia el reconocimiento institucional de estas escuelas. Bajo el influjo de la paidología y gracias a la difusión de teorías de la Escuela Nueva, especialmente las de Montessori y Decroly, las escuelas de párvulos empezaban a contar con una base teórico-práctica propia y a ocupar un lugar más relevante dentro del sistema educativo, aunque a nivel práctico la extensión y dotación de las mismas no tuvieran atisbo de producirse. Tal como denunciaba Matilde García del 
Real, la mayoría estaban regentadas por maestras sin preparación especial alguna, reclutadas mediante oposiciones basadas en el mismo temario de las escuelas primarias, maestras que "con rarísimas excepciones, dan en ellas las mismas enseñanzas que darían en una de niñas si les hubiese correspondido" (García del Real, 1924, p. 7).

El primer tercio del siglo xx es conocido como la Edad de Plata de la cultura española: la pintura, escultura, arquitectura, música vivieron unas décadas de esplendor y los cambios en el sistema educativo también fueron ostensibles. El porcentaje de analfabetismo de los mayores de 10 años se redujo del 56,07 \% en 1900 al 23,17 \% en 1940. La escolarización de los niños de 6 a 12 años fue aumentando lentamente llegando en 1935 al 56,6 \% y en 1952 al 69,1 \% (Viñao, 2004). En educación preescolar hubo interesantes ensayos y se dieron a conocer nuevos métodos que, sin embargo, apenas calaron en la actividad diaria de las escuelas. De hecho, Antonio Ballesteros, inspector de enseñanza primaria, afirmaba en 1930, que la educación preescolar estaba casi abandonada en España:

Apenas existen las escuelas que debería haber conforme a las disposiciones de la ley de 1857; y las que funcionan, ni por su modesta instalación, ni por su mobiliario anticuado, ni por su organización deficiente, ni por el número excesivo de párvulos que está a cargo de cada maestra, permiten otra cosa que una labor disciplinaria y verbal, siempre opuesta a la condición inquieta y jovial de los niños que acuden a las clases. (Ballesteros, 1930, p. xvı)

Un caso peculiar fue el desarrollo de la educación preescolar en Cataluña donde la escuela ya había tomado un claro cariz político. En el Congreso Pedagógico Nacional de 1888, celebrado en Barcelona con motivo de la Exposición Universal, se defendió la necesidad de enseñar a los niños en lengua catalana, lo que impulsó la educación preescolar en esa región (González-Agápito, 1991; Martínez Ruiz Funes, 2013).

La ॥ República tuvo escasas repercusiones en nuestra educación preescolar a pesar de que sus planteamientos implicaban reformas políticas y educativas que culminarían los ideales educativos del regeneracionismo $y$, a la vez, un enfrentamiento directo con la Iglesia y con los grupos ideológicos conservadores (el momento de mayor tensión se produjo en 1931 cuando la Constitución declaró España como estado aconfesional y prohibió a las órdenes religiosas ejercer la enseñanza, artículo 26). El primer gobierno socialista de la ॥ República debía enfrentarse a problemas estructurales endémicos como la escasa escolarización, maestros mal formados y con sueldos miserables, falta de escuelas, etc., y apenas tuvo tiempo para plantear medidas, algunas de las cuales, como la secularización o la coeducación, pronto fueron papel mojado por la victoria de la Confederación Española de Derechas Autónomas (CEDA) en 1933. 


\section{La educación preescolar en el franquismo}

La llegada de la dictadura franquista (1936-1975) implicó un freno en los intentos de renovación pedagógica, un freno en los incipientes avances experimentados por la sociedad española y el comienzo de un periodo poco favorable para el desarrollo de la educación dado que el Estado español asumió un papel subsidiario frente a la Iglesia (Mayordomo, 1989). En el franquismo habría que diferenciar al menos dos partes: la primera, hasta finales de los 50 y, la segunda, hasta mediados de los 70. En esta segunda parte, hubo tres planes de desarrollo que prestaron una atención importante a la educación y que no podemos analizar ahora.

Desde los primeros momentos de la Guerra Civil española, se empezó a divulgar como pensamiento pedagógico único del régimen franquista el deseo de construir una "nueva Escuela española" fundamentada en los pedagogos clásicos, en la doctrina expuesta por la Iglesia en la encíclica Divini Illius Magistri y en los principios políticos de corte fascista (Pozo y Braster, 2013). Durante la dictadura, la religión del Estado fue el catolicismo y la educación religiosa era obligatoria en todas las instituciones educativas, incluso en la universidad, por primera vez en nuestra historia (Puelles, 2006). La Iglesia podía, además, inspeccionar cualquier centro docente.

En estos años no podemos hablar de competición entre el Estado y la Iglesia, sino de delegación de aquél en esta. Si hasta la ॥ República podíamos hablar de desconfianza entre la Iglesia y el Estado con relación a la educación, en el franquismo, la delegación que el Estado hace en la Iglesia podría interpretarse como confianza plena. El movimiento pedagógico de la Escuela Nueva y el principio de "actividad" se borraron primero de la memoria colectiva para sufrir luego un interesante proceso tal como describen Mar del Pozo y Saaj Braster (2013).

Durante el franquismo, el deseo de mantener a la mujer en el hogar ensalzando su papel como madre y esposa y las campañas a favor de la natalidad, hacían innecesaria la educación preescolar. Se llega a afirmar, en 1943, que, en esa edad, "la acción educativa queda limitada a la esfera de la familia y de la Iglesia" y que descuidar esos años "sería entregar la formación de los hijos a extraños influjos; durante estos años los niños son casi exclusivamente de la familia. Ella es la única responsable y su acción puede ser salvadora para sus hijos" (Bohigas, citado en Monés, 1991, p. 166).

Sin embargo, la progresiva incorporación de las mujeres al mundo laboral, aunque escasa, y la extensión de la convicción de la importancia de la educación recibida antes de los seis años, favoreció la expansión de las escuelas de párvulos a partir de los años cincuenta, a pesar de la escasez de oferta de plazas gratuitas. En las primeras décadas del franquismo el modelo educativo era una pirámide invertida pues se había abandonado la 
base, la enseñanza primaria (que incluía la educación preescolar), mientras que se mantuvo e incluso se desarrolló, la educación superior. Esto es particularmente interesante para explicar la respuesta de la red privada ante la demanda de educación preescolar. La escasez de oferta pública provocó un empeoramiento en las condiciones de la oferta existente y un aumento paralelo de la oferta privada (Núñez, 1992). Ambas respuestas suelen darse a la vez, como ocurrió en el franquismo, con el predominio de una sobre la otra dependiendo del nivel educativo y, posiblemente, del nivel de renta de las familias.

Las dos leyes más importantes del franquismo en educación fueron las de 1945 y 1970. La Ley de 17 de julio de 1945 sobre Educación Primaria era muy explícita. Afirmaba que la escuela española tenía que ser ante todo católica y reconocía a la Iglesia "el derecho que de manera supereminente, e independiente de toda potestad terrena, le corresponde para la educación por títulos de orden sobrenatural y la potestad que le compete, cumulativamente con el Estado, de fundar Escuelas de cualquier grado" (Preámbulo). La educación preescolar se mantuvo como el primer nivel de la escuela primaria dividiéndose, según el artículo 18 a y b, en escuelas maternales (hasta los 4 años) y escuelas de párvulos (de 4 a 6 años).

Hubo que esperar a la Ley General de Educación-LGE- de 6 de agosto de 1970 para que aparecieran cambios importantes en la legislación sobre educación preescolar, aunque no se concretarían hasta unos años después. Con esta ley terminaba legalmente la subsidiariedad del Estado en materia de educación, pues consideraba la educación como función esencial del Estado y como un servicio público fundamental. En esos momentos la tarea a realizar era ingente y se empezó por la educación obligatoria de forma que los cambios más importantes en educación preescolar se realizaron una década después. En la LGE, la educación preescolar aparece como el primer nivel del sistema educativo, no obligatoria y dividida en jardín de infancia (niños de 2 y 3 años) y escuela de párvulos (niños de 4 y 5 años).

El Informe Foessa (Fundación Foessa, 1972) ofrecía una negativa visión de la escolarización obligatoria en España en 1970 y una de las causas que sugería era la poca atención prestada a la educación antes de esa edad, situación que calificaba de "aún más grave" y "anómala" con relación a los países de nuestro entorno ya que hasta 1964 no se superó el $25 \%$ de niños de 2 a 5 años escolarizados (porcentaje obstinado pues en 1908 el $24 \%$ de los niños de 3 a 5 años figuraban como escolarizados, aunque pocos en escuelas de párvulos) y en 1968 solo lo estaba el $57 \%$ de los de 5 años cuando en Francia estaba escolarizado el 100 \%. Entre las previsiones del ॥ Plan de Desarrollo para 1972 estaba la escolarización del $78 \%$ de los niños de 5 años, objetivo que a pesar de ser calificado 
de "modesto" no se pensaba que se pudiera conseguir, pues al establecerse una nueva estructura del sistema educativo con la LGE, los centros de primaria tenían que acoger a todos sus alumnos durante cuatro años más (los ocho cursos de duración de la Educación General Básica) y la demanda de plazas se disparó.

En estas circunstancias, la creación de puestos escolares públicos en educación preescolar no podía ser prioritaria para el Estado. La iniciativa privada, mayoritariamente de la iglesia católica, respondió porcentualmente con más plazas, tanto en la educación obligatoria como en educación preescolar. La Iglesia estaba tomando así posiciones en unos momentos de fuertes cambios económicos y políticos por coincidir el final de esta década con la muerte de Francisco Franco (1892-1975) y el comienzo de la democracia. A partir de los Pactos de la Moncloa de 1977 se acordó, dentro del Plan Extraordinario de Escolarización, la creación de 200000 nuevas plazas de educación preescolar públicas fundamentalmente para niños de 4 y 5 años de forma que en 1979-1980 estaba escolarizado ya más del $80 \%$ de los niños de esas edades.

Con relación a los métodos pedagógicos, apenas hay normas hasta los Cuestionarios de Enseñanza Primaria de 1953, lo que no implica que no hubiera una orientación muy clara sobre los contenidos y la metodología evidentes a través del análisis de los libros de texto que reflejan la postura oficial. Es palpable la ideologización de los niños a través del texto y de las imágenes de las cartillas utilizadas para la enseñanza de la lectoescritura que eran prácticamente los únicos materiales que se elaboraban para la educación preescolar. Sin embargo, la educación preescolar, al no ser obligatoria, soportó una presión menor que la primaria y podemos ver ejemplos de renovación pedagógica ya en los años cincuenta cuando el término actividad empezó a adquirir connotaciones positivas. Este movimiento empezó de la mano del método Montessori quizá porque al estar incluida dentro de la ortodoxia católica, estaba entre los "pedagogos visibles", lo que facilitó que se publicaran algunos de sus textos y que se organizaran escuelas según su método (Pozo y Braster, 2013). En los años sesenta los movimientos de renovación pedagógica se identificaron más con otras metodologías como las de Decroly o Freinet.

\section{La educación preescolar en la España democrática: generalización}

Los cambios producidos en la sociedad española desde finales de los años setenta, especialmente en lo relativo al papel de hombres y mujeres, a la incorporación de estas a todos los ámbitos, a la estructura familiar, etc., junto con otros cambios relacionados, en general, con la sociedad del 
conocimiento, tienen que reflejarse en el sistema educativo y, por tanto, también en la educación infantil, una vez asumido que la educación (no confundir con escolarización) comienza con el nacimiento.

La Constitución de 1978 declaraba que no había una religión oficial y que "Los poderes públicos tendrán en cuenta las creencias religiosas de la sociedad española y mantendrán las consiguientes relaciones de cooperación con la Iglesia Católica y las demás confesiones" (artículo 16.3). Esta obligación de cooperación aseguraba a la Iglesia católica el derecho a crear centros educativos y el derecho a recibir subvenciones que los sucesivos gobiernos han mantenido.

A partir de 1975, la demanda de plazas de educación preescolar se disparó, por motivos socioeconómicos más que pedagógicos, siendo la iniciativa privada, y dentro de esta, los centros concertados de la Iglesia (centros privados pagados con fondos públicos), los que respondieron a la demanda. La educación concertada tiene un papel importante en el sistema educativo español pues acoge alrededor del $30 \%$ de los niños (Martínez Torrón, 2005).

Tras la LGE, el cambio más sustancial fue la inclusión de los primeros años de vida dentro de la educación infantil. Así, la Ley de Ordenación General del Sistema Educativo (Logse) aprobada en 1990, dividía la educación infantil en dos ciclos, de cero a dos y de tres a cinco años considerándose que ambas eran educativas. Sin embargo, la Ley Orgánica de Calidad de la Educación (LOCE), en el 2002, dividía la Educación Infantil en dos ámbitos, uno de carácter educativo-asistencial entre los cero y los tres años, denominado Educación Preescolar, y un segundo nivel, Educación Infantil, de carácter educativo, entre los 3 y los 6 años. La Educación Preescolar (de 0 a 3 años) no se incluía como un nivel educativo dentro de las enseñanzas escolares de régimen general, aspecto que fue contestado en los sucesivos Informes del Consejo Escolar del Estado. La LOCE no llegó a aplicarse, ya que la Ley Orgánica de Educación aprobada en el 2006, LOE, planteaba volver a la estructura regulada en la Logse, de tal forma que la Educación Infantil es hoy considerada como un nivel educativo con identidad propia que atiende a niños y niñas desde su nacimiento hasta los 6 años, con dos ciclos: de 0 a 2 y de 3 a 6 . Otra medida importante fue la introducción gradual de la gratuidad en el segundo ciclo de educación infantil a partir de 2004-2005 de forma que desde 2006-2007 es gratuita en los centros públicos y concertados, lo que contribuyó notablemente al aumento de la escolarización de los niños de 3 años (era ya casi total la de niños de 4 y 5 años).

Una de las ideas más repetida en los últimos años en documentos oficiales, tanto del Ministerio de Educación como del Consejo Escolar del Estado y de distintas autonomías (las Comunidades Autónomas tienen plenas 
competencias en educación), es que "la generalización de la educación infantil aporta un elemento fundamental de prevención del fracaso y constituye un factor de equidad de primer orden" (MEC, 2004, p. 26). Por tanto, la educación infantil, que desde su creación se debatió entre las funciones asistencial y educativa (recordemos el debate que se produjo con la LOCE), se encuentra ahora ocupando un papel estrella en el sistema educativo. Además de tener un carácter educativo propio, se le encomienda un papel de enorme responsabilidad que solo podrá cumplir si el esfuerzo para superar situaciones de partida desfavorecidas se mantiene en los siguientes niveles del sistema educativo y si se estrecha la relación entre familias y escuela.

España es hoy uno de los países líderes en escolarización preescolar al estar escolarizado prácticamente el $100 \%$ de los niños de 3, 4 y 5 años. En concreto, en 2016-2017, lo estaba el 96,3\% de los niños de tres años siendo el porcentaje de escolarización algo mayor para los de cuatro y cinco (Ministerio de Educación y Formación Profesional, 2019). Los cambios cuantitativos y cualitativos producidos en los últimos años han sido enormes y manifiestan un apoyo claro desde todas las instancias implicadas por lograr la total escolarización en el segundo ciclo de la educación infantil y el incremento de la oferta de plazas gratuitas en el primero, de forma que se responda adecuadamente a las necesidades de las familias.

\section{Conclusiones}

En este artículo se han descrito tres etapas cuyas características pueden trasladarse, con los ajustes oportunos, a otros contextos, en los que deberán contemplarse numerosos factores, pues estamos ante procesos complejos. En el caso español se aprecia que, a pesar de las distintas ideologías que se han sucedido en el gobierno en los últimos 200 años, funciona la teoría de dependencia de paso, ya que los sucesivos gobiernos solo introducen algunos cambios sobre lo que encuentran: la educación preescolar se consideró desde el primer momento como una preparación para la escuela primaria y esa perspectiva escolar ha primado llegando a identificarse educación preescolar con escolarización temprana y a olvidarse que la educación es un concepto más amplio que el de escuela. Este aspecto abre un debate que deberá afrontarse para que la educación infantil cumpla con sus objetivos.

Los modelos que hemos citado al principio deben tomarse como modelos "ideales": permiten estudiar si en un país o en un momento dado se está más cerca de uno o de otro, aunque no siempre es fácil distinguir entre ambos. Así, en España ha primado el modelo de conciliación hasta 1975, ya que el objetivo no era la plena escolarización de los niños de esas edades, sino atender a los niños que lo necesitaban. Sin embargo, a

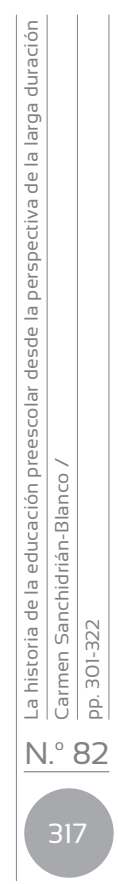


la vez, las escuelas de párvulos eran escuelas, dependían del Ministerio de Educación, y su primer objetivo era educativo, por lo que, de acuerdo con ese modelo, tendría que haberse intentado pronto su generalización. Por otra parte, en los últimos años se ha reforzado la orientación educativa, se ha generalizado a todos los niños, pero ha sido por motivos socioeconómicos más que pedagógicos. Es decir, la educación preescolar siempre ha estado dentro del sistema educativo y esto ha marcado sus características, pero impulsada por el modelo de conciliación.

Las hipótesis de partida planteadas se comprueban en el caso español, donde se aprecian claramente las tres etapas y donde conocer el papel de la Iglesia y el Estado y las relaciones entre ambos, es imprescindible. La utilización en otros contextos de las etapas y modelos descritos permitirá comprobar si, efectivamente, son útiles para explicar la diversa evolución de la educación preescolar, incluso en países cercanos y pertenecientes a contextos socioculturales no muy distintos.

\section{Referencias}

Ballesteros, A. (1930). Notas preliminares. En V. Neyrinck, La educación en las escuelas de párvulos (pp. v-xvII). Librería y Casa Editorial Hernando.

Baudouin, J. M. (1866). La enseñanza primaria y especial en Alemania (A. Rius trad.). Librería de Juan Bastinos e Hijo Editores.

Boyd, C. (1997). Historia patria: Politics, history, and national identity in Spain, 1875-1975. Princeton University Press.

Burger, K. (2014). Entanglement and transnational transfer in the history of infant schools in Great Britain and salles d'asile in France, 1816188. History of Education, 43(3), 304-333. http://dx.doi.org/10.1080/ 0046760X.2014.888486

Carderera, M. (1859). Jardines de la infancia. Anales de Primera Enseñanza, 35, 1029-1034.

Castells, J. (1973). Las asociaciones religiosas en la España contemporánea: Un estudio jurídico-administrativo (1767-1965). Taurus.

Constitución Española. Boletín Oficial del Estado, 29 de diciembre de 1978, 311, 29313- 29424. https:/www.boe.es/eli/es/c/1978/12/27/(1)/con

David, P. A. (2007). Path Dependence-A Foundational Concept for Historical Social Science. Cliometrica: The Journal of Historical Economics and Econometric History, 1(2), 91-114. https://doi.org/10.1007/s1169 8-006-0005-x

Dorado Soto, M. A. (1984). Reglamentación de la educación de párvulos en España (1876-1900). Significado de las reformas de Albareda y de Pidal. Anales de Pedagogía, 2, 29-55. https://revistas.um.es/analespedagogia/article/view/288511/209691 
Fernández Soria, J. M. (2013). Municipio y Educación en España (siglos XIX-Xx). En Á. Adão e J. Magalhães (Coords.). História dos Municípios na Educação e na Cultura: incertezas de ontem, desafios de hoje (pp. 165-193). Instituto de Educação da Universidade de Lisboa. http://hdl.handle.net/10451/9460

Fundación Foessa. (1972). Síntesis del informe sociológico sobre la situación social de España, 1970. Euramérica.

García del Real, M. (1924). Nuestras escuelas de párvulos. Tipografía del Asilo del Niño Jesús.

García Navarro, P. de A. (1874). Estudios pedagógicos: Fröebel y los jardines de infancia. Imprenta y estereotipia Aribau.

García Navarro, P. de A. (1879). Manual teórico- práctico de enseñanza de escuelas de párvulos según el método de los jardines de la infancia de F. Froebel. Colegio Nacional de Sordo Mudos y Ciegos. https://sirio.ua.es/libros/BEducacion/parvulos/ima0002.htm

García Navarro, P. de A. (1913). Manual teórico-práctico de enseñanza de escuelas de párvulos según el método de los jardines de la infancia de F. Froebel (4. ${ }^{a}$ ed.). Librería de los sucesores de Hernando.

González-Agapito, J. (1991). Educación infantil e industrialización en Cataluña. Historia de la Educación, 10, 135-154. http://revistas.usal. es/index.php/0212-0267/article/viewFile/6916/6897

López Catalán, J. (1864-1867). El arte de educar. Curso completo de Pedagogía Teórico Práctica aplicada a las escuelas de párvulos, 4 volúmenes. Juan y Antonio Bastinos.

López Catalán, J. (1887). El froebelianismo puro y neto. Librería de Juan y Antonio Bastinos. http://bdh-rd.bne.es/viewer.vm?id=0000085526\&page=1

Luc, J-N. (1982). La petite enfance à l'école, xıxe-xxe siècles: textes officiels relatifs aux salles d'asile, aux écoles maternelles, aux classes et sections enfantines (1829-1981). INRP

Mahoney, J. (2000). Path dependence in historical sociology. Theory and Society, 29(4), 507-548. https://www.jstor.org/stable/3108585?seq=1

Martínez Ruiz Funes, M. J. (2013). La cultura material y la educación Infantil en España. El método Froebel (1850-1939) [Tesis de doctorado]. Murcia, Universidad de Murcia. http://digitum.um.es/xmlui/ bitstream/10201/30144/1/TESIS\%20formato\%20digital.pdf

Martínez-Torrón, J. (2005). School and religion in Spain. Journal of Church \& State, 47(1), 133-150. https://doi.org/10.1093/jcs/47.1.133

Mayordomo, A. (1989). Historia de la educación en España: Textos y documentos. Nacional-catolicismo y educación en la España de la posguerra. T. 5, 2 vols. Ministerio de Educación Cultura y Deporte. https://sede.educacion.gob.es/publiventa/descarga.action?f_codigo_agc=1408_19 
Ministerio de Educación y Ciencia. (2004). Una educación de calidad para todos y entre todos. Propuestas para el debate. MEC. https://sede. educacion.gob.es/publiventa/descarga.action?f_codigo_agc=18944

Ministerio de Educación y Formación Profesional. (2019). Sistema estatal de indicadores de la educación 2019. Ministerio de Educación y Formación Profesional. http://www.educacionyfp.gob.es/dam/jcr:627dc544-8413-4df1-ae46-558237bf6829/seie-2019.pdf

Monés, J. (1991). La educación preescolar en España desde el final de la Guerra Civil hasta los años 60. Historia de la Educación, 10, 155185. http://revistas.usal.es/index.php/0212-0267/article/view/6917

Montesino, P. (1840). Manual para los maestros de escuelas de párvulos. Imprenta Nacional. https://books.google.es/books/about/Manual_ para_los_maestros_de_escuelas_de.html?id=B87RXG9P9VsC\&redir_esc $=y$

Núñez, C. E. (1992). La fuente de la riqueza. Educación y desarrollo económico en la España contemporánea. Alianza Universidad.

Ossenbach, G. (2001). Génesis histórica de los sistemas educativos. En J. L. García Garrido, G. Ossenbach y J. M. Valle, Génesis, estructuras y tendencias de los sistemas educativos iberoamericanos (pp. 13-60). Organización de Estados Iberoamericanos.

Pierson, P. (2000). Increasing Returns, Path Dependence, and the Study of Politics. The American Political Science Review, 94(2), 252-267. https://www.jstor.org/stable/2586011? origin=JSTOR-pdf\&seq=1

Pozo, M. M. del y Braster, S. (2013). El movimiento de la Escuela Nueva en la España franquista (España, 1936-1976): repudio, reconstrucción y recuerdo. Revista Brasileira de História da Educação, 12(30), 15-44. http://dx.doi.org/10.4322/rbhe.2013.002

Puelles, M. de (1980). Educación e ideología en la España contemporánea. Labor.

Puelles, M. de (2006). Religión y escuela pública en nuestra historia: Antecedentes y procesos. Bordón, 58(4-5), 521-535. https://recyt.fecyt. es/index.php/BORDON/article/view/39580

Ruiz Berrio, J. (1982). En el centenario de Froebel: La introducción de su método en España. Revista de Ciencias de la Educación, 112, 439-446.

Sanchidrián, C. (1985). A brief analysis of the qualitative and quantitative evolution of Early Childhood Education in Spain (1970-1984). En E. Catarsi (Ed.), Twentieth century pre-school education: Times, Ideas and portraits (pp. 159-167). Franco Angeli.

Sanchidrián, C. (1991). Funciones de la escolarización de la infancia: Objetivos y creación de las primeras escuelas de párvulos en España. Historia de la Educación, 10, 63-87. http://revistas.usal.es/index. php/0212-0267/article/view/6913 
Sanchidrián, C. (2009). La extensión de la escolaridad temprana como síntoma y resultado del cambio educativo y social. En R. Berruezo y S. Conejero (Coords.). El largo camino hacia una educación inclusiva: la educación especial y social del siglo XIX a nuestros días, vol. 2 (pp. 451-462). UPNA.

Sanchidrián, C. (2010). Historia de la infancia. Historia de la educación infantil. En J.-L. Guereña, J. Ruiz Berrio y A. Tiana (Eds.). Nuevas miradas historiográficas sobre la educación en España de los siglos XIX y xx (pp. 67-104). Ministerio de Educación. https://sede.educacion. gob.es/publiventa/PdfServlet?pdf=VP15146.pdf\&area $=\mathrm{E}$

Sanchidrián, C. (2015). The role of the State and the Church in the development of early childhood education in Spain (1874-1975). En H. Willekens, K. Scheiwe y K. Nawrotzki (Eds.), The development of early childhood education in Europe and North America (pp. 92111). Palgrave MacMillan.

Sanchidrián, C. (2017). Las maestras de párvulos: ¿Madres o maestras? Revista Linhas,18(38), 11-40. http://dx.doi.org/10.5965/198472381 8382017011

Sanchidrián, C. y Ruiz Berrio, J. (Coords.) (2011). La educación infantil en los sistemas educativos. Graó.

Scheiwe, K. y Willekens, H. (2009). Introduction: Path-dependencies and change in child-care and preschool institutions in Europe-historical and institutional perspectives. En K. Scheiwe y H. Willekens (Eds.). Child care and preschool development in Europe: Institutional perspectives (pp. 1-22). Palgrave Macmillan.

Sommer, D., Pramling, I. y Hundeide, K. (2010) Child perspectives and children's perspectives in theory and practice. Springer.

Valiente, C. (2009). Child Care in Spain after 1975: The Educational Rationale, the Catholic Church, and Women in Civil Society. En K. Scheiwe y H. Willekens (Eds.). Child care and preschool development in Europe: Institutional Perspectives (pp. 72-87). Palgrave Macmillan.

Valiente, C. (2011). (Pre)School is not childcare. Preschool and primary school education in Spain since the 1930s. En K. Hagemann; K. H. Jarausch y C. Allemann-Ghionda (Eds.). Children, families and States: Time policies of childcare, preschool, and primary education in Europe (pp. 220-236). Berghahn Books.

Viñao, A. (1983). Una cuestión actual: sobre el academicismo en la enseñanza preescolar en el siglo xIx. Historia de la Educación, 2, 179187. http://campus.usal.es/ revistas_trabajo/index.php/0212-0267/ article/viewFile/6513/6512

Viñao, A. (2002). Sistemas educativos, culturas escolares y reformas: Continuidades y cambios. Morata. 
Viñao, A. (2004) Escuela para todos: Educación y modernidad en la España del siglo xx. Marcial Pons.

Viñao, A. (2014). Religión en las aulas: Una materia controvertida. Morata.

Whitbread, N. (1972). The evolution of the nursery-infant school: A history of infant and nursery education in Britain. Routledge and Kegan Paul.

Willekens, H. y Scheiwe, K. (2020). Looking back: Kindergarten and preschool in Europe since the late $18^{\text {th }}$ century. A short comparative study of pioneers and laggards. Universitätsverlag. https://hildok.bszbw.de/frontdoor/index/index/docld/1094

Willekens, H., Scheiwe, K. y Nawrotzki, K. (Eds.). (2015). The development of early childhood Education in Europe and North America. Palgrave MacMillan. 